Article

\title{
Evaluating Accessibility Benefits of Opening Gated Communities for Pedestrians and Cyclists in China: A Case Study of Shanghai
}

\author{
Senqi Yang, Wenken Tan * and Longxu Yan \\ College of Architecture and Urban Planning, Tongji University, Shanghai 200092, China; \\ senqiyang@tongji.edu.cn (S.Y.); lolonger@tongji.edu.cn (L.Y.) \\ * Correspondence: twk@tongji.edu.cn
}

Citation: Yang, S.; Tan, W.; Yan, L. Evaluating Accessibility Benefits of Opening Gated Communities for Pedestrians and Cyclists in China: A Case Study of Shanghai. Sustainability 2021, 13, 598. https://doi.org/ $10.3390 /$ su13020598

Received: 25 October 2020 Accepted: 5 January 2021 Published: 10 January 2021

Publisher's Note: MDPI stays neutral with regard to jurisdictional clai$\mathrm{ms}$ in published maps and institutional affiliations.

Copyright: () 2021 by the authors. Licensee MDPI, Basel, Switzerland. This article is an open access article distributed under the terms and conditions of the Creative Commons Attribution (CC BY) license (https:// creativecommons.org/licenses/by/ $4.0 /)$.

\begin{abstract}
Opening gated communities (GCs) has been widely discussed for urban inclusion and revitalization. With the policies of opening GCs being promoted in China, the quantitative and comprehensive evaluation of the potential benefits is heavily needed. Taking Shanghai as an example, this study quantifies and analyzes the accessibility benefits and risks of opening GCs for pedestrians and cyclists considering two GC types, two opening levels, two travel modes, and different facilities. We found that (1) opening GCs can bring $50 \mathrm{~m}+$ accessibility gains to $17 \%$ and $52 \%$ of the residents in moderate opening (MO) and complete opening (CO) scenarios, respectively. (2) Cyclists benefits more than pedestrians in all scenarios. (3) Conventional GCs have fewer benefits in $\mathrm{MO}$ but more in $\mathrm{CO}$ than newly established ones. Trips to bus stations demonstrate the largest accessibility gains. (4) The accessibility benefit of a residential building is highly determined by its closeness to the gates and relative location in the block. (5) Only 1\% and 5-7\% of external trips may penetrate the opened communities in $\mathrm{MO}$ and $\mathrm{CO}$ scenarios, respectively, which are far less than both the expectation and the benefits. Finally, several local design guidelines are proposed.
\end{abstract}

Keywords: gated communities; opening scenarios; accessibility benefits; evaluation; shanghai

\section{Introduction}

The gated community (GC) is a longstanding residential estate pattern in China. Urban organization in the early phase of China's foundation was greatly influenced by development methods in the Soviet Union, in which an ideal "generalized" space form was self-sufficient and able to offer its residents most daily functions, including housing, working, and other services [1,2]. Therefore, in China, large numbers of gated "work units", where residence and employment are well balanced, were created and formed to be a typical Chinese cityscape [3,4]. After China's reform and opening up since the 1970s, the "acquaintance society" in the conventional GCs started to confront disintegration and renewal [5]. Meanwhile, the new housing estates developed by private companies took the form of GCs, making them one of the dominant forms of residential estates in China in both urban and rural areas $[4,6]$.

Though widely adopted, GCs are criticized for negatively affecting both the internal living quality and external urban environments, especially for bringing inconvenience to both pedestrians and cyclists. As for interior residents, they have to take the strain of high housing prices and property costs [7] but are unable to enjoy public spaces inside the neighboring communities due to inconvenient transportation, which significantly affects slow traffic. Moreover, without connections to a larger urban environment, the semi-private internal streets in GCs can hardly support a social life, with insufficient diversity of pedestrians [8]. As for the exterior urban area, GCs foster traffic congestion and high automobile dependency [9]. Researchers estimate that residents from GCs in superblocks use $65 \%$ to $80 \%$ more transit energy than those living in mixed-use, walkable 
neighborhoods [10]. Furthermore, GCs also cause fragmentation and polarization in sociocultural aspects [11]. All these drawbacks inspire the exploration of GCs' opening up. As the urban regeneration in China shifts from "superblock centered" to "street centered" [12], an open block system is strongly promoted by the government. In 2016, "opening gated residential communities to public road systems" was first put forward in official documents, stressing that newly established communities should adopt the block system. Another official document, Shanghai Street Design Guidelines (SSDG), encourages opening the main internal roads in large-scale GCs for pedestrians and cyclists. In 2017, the urban renewal projects represented by opening GCs were launched in a few large Chinese cities, such as Changsha, Chongqing, and Nanjing. Since 2018, the opening policies have been released in middle and small size cities, highlighting the government's attention to the revitalization of GCs and their adjacent urban areas. The exemplary cases are Yulin community in Chengdu, Gubei community in Shanghai, and the Guogongzhuang public rental housing project in Beijing.

Prior studies have explored multiple aspects of GCs' (re)development, involving both the benefits and the risks of opening up. Some researchers found that opening GCs provides great benefits, including enhancing spatial accessibility, strengthening socialcultural connections, and improving low-carbon transport by creating a more walkable and bikeable environment [9]. The opening strategy is also highly praised by urban practitioners. One study demonstrates that for urban planners, adding additional entrances is ranked in second place among multiple spatial interventions in GCs [13]. However, some researchers argue that opening up will negatively affect some households [14]. In a recent study, five types of pressure brought by opening GCs are revealed as site redesign, urban governance, social frictions, legal status, and a financial burden [15]. In summary, no consensus has been reached on the evaluation of opening GCs.

Although the effects of opening GCs have been widely discussed, there still exist some limitations. Most studies, whether they are based on qualitative or quantitative approaches, seldom consider factors such as GCs' characteristics, attributes of pedestrians and cyclists, and travel destinations, which may lead to discrepancies in the estimated benefits of opening GCs. Furthermore, the risks accompanied by opening the gates have been noticed but never measured or surveyed.

Taking Shanghai as an example, this paper focuses on quantifying and analyzing the accessibility benefits for pedestrians and cyclists as well as the potential risks brought by opening the GCs. To incorporate the aforementioned factors, we select two typical GCs and quantify the accessibility benefits for both pedestrians and cyclists and in two opening scenarios, which are designed based on the most common situation of GC renewal rather than the design of new blocks. Moreover, quantitative analysis is carried out by combining activity models and the data from the Comprehensive Transportation Survey, census data, and online maps.

This paper is organized as follows: Section 2 provides a literature review of GC formation and influences. Section 3 describes our metrics, scenario design, and data processing. Section 4 evaluates the overall accessibility benefits of opening GCs and explores the discrepancies between two communities, cyclists and pedestrians, different categories of facilities, and different scenarios. Finally, Section 5 presents the conclusion and discussion.

\section{Literature Review}

\subsection{Gated Community Formation and Urban Development in China}

The gated community (GC) is a form of neighborhood with secured entrances and boundaries created by walls, fences, and other barriers. According to the evolution of GCs revealed by Blakely and Snyder (1997), GCs can be traced back to gated military settlements built by the occupying Romans around $300 \mathrm{BC}$. Not until the latter half of the nineteenth century were the first purely residential gated neighborhoods developed by the upper-income citizens, aiming to insulate themselves from the troublesome industrializing 
cities [16]. During suburbanization in the 1960s, downtowns in many Western cities declined and, consequently, rich people moved to suburbs for a better living environment. In order to attract the middle classes back to downtowns and revitalize city development, many GCs were then built within the cities. In brief, GCs and current urban policies seek similar ends, which is the promotion of the city as a place to live for the middle classes [17].

Being a typical manifestation of enclave urbanism [18], the Chinese GCs are different from the Western form in their larger scale, higher density, and serving mixed-level income classes [19]. The reason for these differences is their unique historical origin, based on which Chinese GCs can be divided into two types. The first type dates to the planned economy period and is still common today in downtown areas of big cities, including Shanghai and Beijing. After the founding in 1949, urban neighborhoods in China were reorganized as "work units" called "dayuan" or "danwei", which emerged as the first form of GCs in China. Gates in these GCs are used to segregate not only residential estates but also the production places and even the power space. For example, administrative bureaus and state-owned companies usually built exclusive communities for employers, where outsiders were ineligible to enter or reside. Since the 1978 economic reform, these productive units have been constantly penetrated by private business, becoming more and more inhomogeneous [19].

Another type of GC has a similar origin to its Western counterparts. As China began to reform and open up after 1978, new housing estates were built outside the old city areas and took the form of GCs that can provide an upmarket neighborhood to attract residents of the increasing middle and upper classes. The new GCs grew rapidly in the metropolitan periphery [20], characterized by large-scale blocks and internalized public space. This type of GC and the renewed productive units in the old city areas together comprise two typical categories of urban GCs in China.

\subsection{Debates about Gated Communities}

A GC produces clear benefits for internal residents. The widely recognized positive effects of GCs includes increased security [21], better privacy [13], greater efficiency in exclusive service provision [22,23], and a stronger sense of place attachment [24]. From another aspect, GCs also offer an escape from outside pollution and vehicles [25].

Nevertheless, considerable amounts of studies also propose that GCs have harmful effects on urban society. Many studies demonstrate that GCs deepen social polarization [26-28]. In one study, GCs are interpreted as an internal simplification which will inevitably increase social tensions and exacerbate social cleavage among communities [29]. A recent study also puts forward that as one of the important spatial representations of gentrification in China, GCs further weaken and destroy neighborhood relationships [11].

Accompanied by such influence exerted on the social structure, the quality of public spaces in GCs also declined. Pseudo-public spaces increased [30] and are characterized by similar, minimum-level facilities (a central green space, sometimes a clubhouse) [19]. The more the public spaces are privatized by the affluent class, the more free-access green space provision decreases [28], which primarily affects low-income renters and leads to many social problems [7].

Additionally, GCs are blamed for negatively affecting urban transportation and the environment as they causes detours for outsiders. GCs are criticized not only for damaging the overall connectivity of urban space but also having a negative effect on the choice of lowcarbon transportation [31]. Recent literature even finds that the main reason pedestrians accessing metro stations were deviating from the shortest station access path is the presence of GCs [32]. Some researchers also demonstrate that the expansion of GCs generates much more traffic congestion and pollution from hydrocarbon emissions [22].

In essence, these hazards are attributed to GCs' negative impact on the openness, transparency, and accessibility of cities [17]. To be more specific, GCs provide huge challenges to the traditional porosity and democracy of the street [21], which triggers the method of opening the gates and reconnecting the roads. Not only can openness erase 
the traffic congestion by expanding the micro-road network [33], it can also increase the overall connectivity and accessibility of the current road network and alleviate the urban traffic problem [34].

As an efficient and low-cost solution to improve the overall isolation of GCs, the opening up method has led to some explorations of its benefits from both socioeconomic and physical aspects. On the social level, one study emphasizes that opening GCs should be exploited to achieve quality urban space to enhance the well-being of the residents [35]. It is also found that without gating, the local commercial value based on the city's street network would be developed [36]. On the physical environment level, one study uses the "permeability" change in network analysis to illustrate the improvement of opening gates [37]. Another study finds that an opened community outperforms a gated one by a 49 percent reduction in time cost, fuel cost, air pollution cost, and noise pollution cost in a hypothetical community scenario [38].

To sum up, the major defect in existing studies is the lack of quantitative evaluation of the accessibility benefits of opening GCs with more realistic factors considered. Though the benefits of opening GCs have been widely discussed in several dimensions with knowledge of multiple disciplines, the significant discrepancies of such benefits between pedestrians and cyclists due to factors including GC types, opening levels, and travel destinations have not yet been adequately revealed. Therefore, this study endeavors to fill the gap by quantitatively evaluating the accessibility benefits of opening GCs for pedestrians and cyclists, regarding two typical Chinese GCs and various opening scenarios. Based on an empirical study, the outcomes may support policymaking in opening implementation and revitalization of GCs in China.

\section{Methodology and Data}

\subsection{Accessibility Benefit Quantification and Metric Design}

This paper quantifies the accessibility benefits combining activity models and assumed GC opening scenarios. An accessibility benefit of opening a GC simply refers to the saving percentages of cumulative travel distances or the proportion of potential routes that with the reduced distances exceed some thresholds. More specifically, the total benefit of distance provided by opening a GC is given by

$$
\begin{gathered}
B_{\text {total }}^{\text {distance }}=\frac{\sum_{i}\left[T_{i} \times \sum_{j} P_{i j}\left(d_{i j}^{\text {barrier }}-d_{i j}^{\text {open }}\right)\right]}{\sum_{i}\left[A_{i} \times \sum_{j} P_{i j} d_{i j}^{\text {barrier }}\right]} \\
P_{i j}=\frac{e^{-\gamma d_{i j}}}{\sum_{j} e^{-\gamma d_{i j}}}
\end{gathered}
$$

where $d_{i j}^{\text {barrier }}$ is the present travel distance from residential building $\mathrm{i}$ to a destination $\mathrm{j}$ without any opening procedure, $d_{i j}^{o p e n}$ is the travel distance from $i$ to $j$ under a scenario in which some new gates are opened. $P_{i j}$ is the travel probability from $i$ to $j$ that is calculated by a single-constrained gravity model, $T_{i}$ is the total numbers of trips that originate from $\mathrm{i}$, so that the products $T_{i} \times \sum_{j} P_{i j} d_{i j}^{\text {open }}$ and $T_{i} \times \sum_{j} P_{i j} d_{i j}^{\text {barrier }}$ refer to the cumulative travel distances that originate from i with or without any GC opening policy.

To provide a more precise quantification, $T_{i}$ is further subdivided into different activity types and corresponding facilities. This paper takes into account four types of facilities: bus station, metro station, daily services, and sports and entertainment. The latter two categories are extracted by combining the activity types defined in the comprehensive transportation survey in Shanghai and the point of interest (POI) types defined by the online mapping services in China so that $T_{i}$ can be well estimated based on real activity patterns.

$$
T_{i}^{k}=A_{i} D_{p o p} \mu^{k}
$$


where $A_{i}$ is the residential building area of building $\mathrm{i}, D_{\text {pop }}$ is the average population density in Shanghai regarding the residential building area, and $\mu^{k}$ is the average travel frequency (person/day) regarding facility $\mathrm{k}$.

The metric $B_{\text {total }}^{\text {distance }}$ measures the absolute savings in travel distance when gates are opened. However, since the detours caused by community gates are generally limited by the size of urban blocks (e.g., $100 \mathrm{~m}$ ), the fraction of the total travel distances would be comparatively small if we consider trips as long as, e.g., $2 \mathrm{~km}$. In fact, since people choose to walk mostly when travel distances are less or around $400 \mathrm{~m} \mathrm{[39],} \mathrm{a} \mathrm{saving} \mathrm{of}$ $50 \mathrm{~m}$ in opening scenarios may be sufficiently perceptible for people to support and act for such policies.

Therefore, in order to eliminate the effect of travel distance on the absolute accessibility benefit $B_{\text {total }}^{\text {distance }}$, we propose another metric $B_{\text {total }}^{\text {count }}$, which measures the proportion of benefitted ODs that have their distances dropped by at least $50 \mathrm{~m}$ :

$$
B_{\text {total }}^{\text {count }}=\frac{\sum_{i} \sum_{j} A_{i} P_{i j} I\left(d_{i j}^{\text {barrier }}-d_{i j}^{\text {open }}>50 m\right)}{\sum_{i} \sum_{j} A_{i} P_{i j}}
$$

where $I$ is an indicator function to detect whether the saved distance exceeds $50 \mathrm{~m}$. If $10 \%$ of the trips involve accessibility improvements, even though the average distance $\left(B_{\text {total }}^{\text {distance }}\right)$ savings are relatively small, an opening policy may still be welcomed. Finally, it should be noted that both $B^{\text {distance }}$ and $B^{\text {count }}$ can be calculated either by aggregating the trips originating from all buildings in one community or from each building to specific facilities.

Moreover, the penetration risk risk ${ }^{\text {count }}$ is defined in a similar way to $B_{\text {total }}^{\text {count }}$,

$$
\text { risk }^{\text {count }} \frac{\sum_{i} \sum_{j} B_{i} P_{i j} I\left(d_{i j}^{\text {barrier }}-d_{i j}^{\text {open }}>50 m\right)}{\sum_{i} \sum_{j} B_{i} P_{i j}}
$$

where $B_{i}$ is the residential building area of building $i$ that is located within the neighboring $500 \mathrm{~m}$ from the case communities. Again, we presume that if the saved distance exceeds $50 \mathrm{~m}$, the neighboring residents may choose to penetrate the opened GCs.

\subsection{Scenario Design}

As summarized in Table 1, two scenarios are modeled. One is the moderate opening scenario (MO), in which the fake gates, those built but not actively used, are assumed to be opened. Note that there are two types of fake gates, as shown in Figure 1. Some fake gates, namely locked gates, are set but completely closed, blocking all potential walkers, cyclists, and automobiles. Other fake gates, namely pedestrian gates, are equipped with rotating doors so that all access is restrained except for walkers. To demonstrate such a difference, we measure the accessibility benefits for walking and bicycles, respectively.

\begin{tabular}{|c|c|c|c|}
\hline Scenario & Definition & $\begin{array}{c}\text { Affected Travel } \\
\text { Modes }\end{array}$ & Gated by \\
\hline \multirow[t]{2}{*}{ Current situation } & No opening policy & Walking & Wall + pedestrian gates \\
\hline & & Cycling & $\begin{array}{c}\text { Wall }+ \text { pedestrian gates }+ \\
\text { locked gates }\end{array}$ \\
\hline Moderate opening & Open existing gates & Walking and Cycling & Walls \\
\hline Complete opening & Break the walls & Walking and Cycling & Almost none \\
\hline
\end{tabular}

Table 1. Scenario design. 


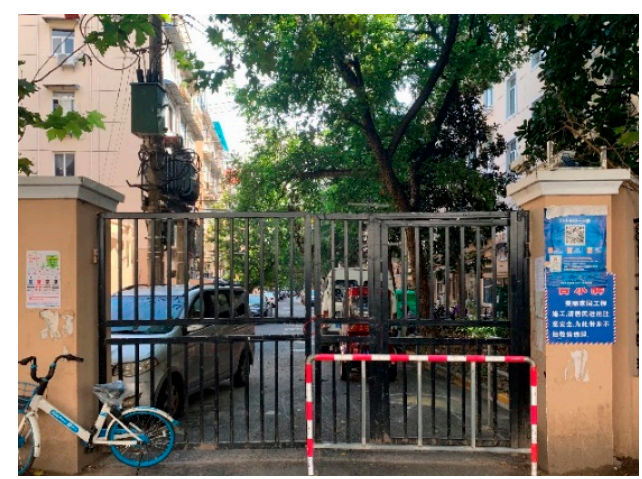

(a)

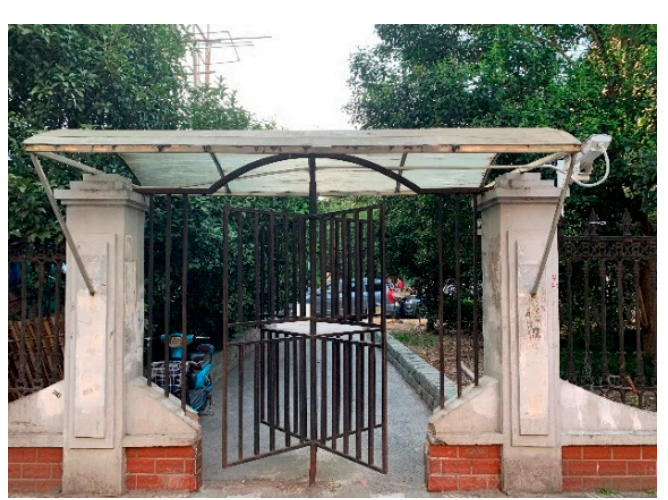

(b)

Figure 1. Examples of locked gates (a) and pedestrian gates (b).

Another scenario is the complete opening scenario (CO), in which we not only open the fake gates but also add new gates with a reasonable interval distance by breaking the walls. The new gates are determined mainly based on the grids of the major roads within the community, which should be planned as entrances from the perspective of the latest opening community policy.

Figure 2 depicts a virtual community with two existing gates (where the community roads are linked directly to the city road network) and one fake gate (the thick red line). As one can expect, when no opening policies are implemented, the residents in building $\mathrm{O} 1$ suffer the most from the gates and walls, while residents in building $\mathrm{O} 3$ can easily access $\mathrm{D} 1$ or D3 by walking but cycling. In contrast, $\mathrm{O} 1$ generally has better accessibility to all facilities. In MO, as the only fake gate will be opened, $\mathrm{O} 3$ benefits significantly for $\mathrm{D} 1$ and D3. $\mathrm{O} 1$ and $\mathrm{O} 2$ also benefit slightly for $\mathrm{D} 1$. In $\mathrm{CO}$, four new entrances (green nodes) will be added considering the grid of the major community roads and the intervals. $\mathrm{O} 2$ and $\mathrm{O} 3$ will benefit remarkably for the facilities in the direction of D2 and D1, respectively. O1 will also benefit slightly for some facilities.

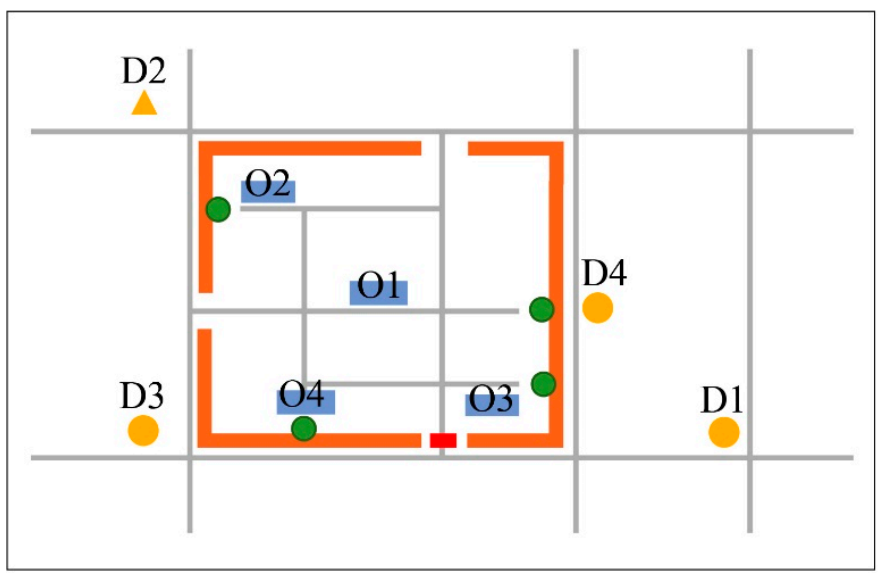

Legend

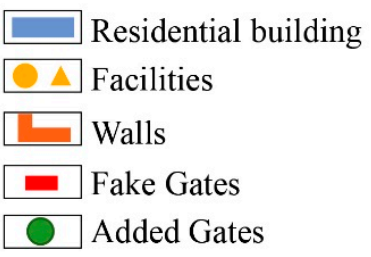

Figure 2. Diagram of a virtual gated community.

\subsection{Data Preprocessing and Case Selection}

Two cases are chosen according to different formations and developments of GCs mentioned in Section 2.1. The Yangpu community is the first type of GC in the old city, developed from working units which have a history of more than half a century. The Pudong community is the second type of new GC in new urban areas, characterized by a larger block size and community-owned central public space. As shown in Figure 3, the research area is delimited within $2 \mathrm{~km}$ of each community, considering the general tolerance of pedestrians and cyclists. Since the detours caused by GCs are generally limited 
by the size of urban blocks, the benefit brought by opening the gates for long-distance travel by car is negligible.
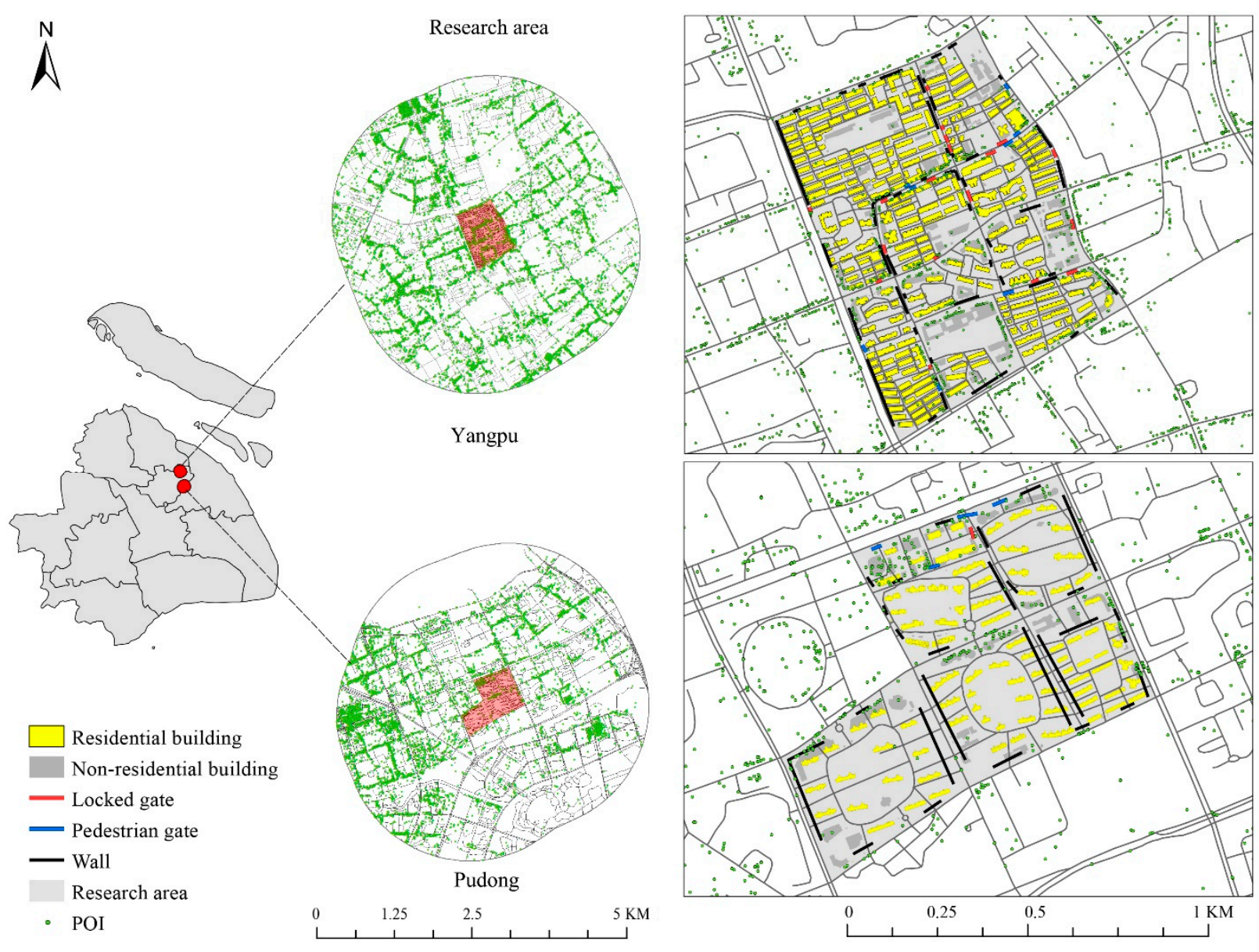

Figure 3. Research cases.

Four categories of facilities are encompassed, which are bus station, metro station, daily services (shopping, catering, and services), and sports and entertainment. The first two categories are considered because they are the most common facilities related to daily mobility. The latter two categories are extracted by combining the activity types defined in the Comprehensive Transportation Survey in Shanghai and the point of interest (POI) types defined by the data provider in China (amap.com, one of the largest online mapping services in China). The activity frequencies of residents visiting different facilities $\left(\mu^{k}\right)$ are derived from the Comprehensive Transportation Survey. The number of residents in each parcel was taken from each district available in the census report based on the floor area of each parcel.

\section{Results}

\subsection{Overall Accessibility Benefits}

In general, we find that opening GCs can provide significant accessibility benefits, which, however, may vary dramatically as the metric changes. When measured by reductions in the cumulative trip distance $\left(b^{\text {dist }}\right)$, this benefit is seemingly limited. As shown in Table 2 in both Yangpu and Pudong cases, MO improves walking and cycling accessibilities by no more than $3 \%$ and $5 \%$, respectively. Even in the CO scenario, which removes all the surrounding walls, the reduction percentages of trip distances by walking and cycling are only $5.7 \%$ and $11.8 \%$. The numbers are small due to two reasons. On the one hand, opening the GCs mainly reduces the detour distances within the communities, which are 
naturally limited to no more than the size of urban blocks, generally producing constrained values of the nominator of $b^{\text {dist }}$. On the other hand, our evaluation takes into account the destinations with distances up to $2 \mathrm{~km}$ to the origins, which may generate relatively long trips and increase the values of the denominator of $b^{\text {dist }}$. In the case of $1 \mathrm{~km}$ trips, a $5 \%$ saving in the distance on average equals a $50 \mathrm{~m}$ reduction, which could be a subjectively perceivable benefit.

Table 2. Overall accessibility benefits.

\begin{tabular}{ccccc}
\hline & \multicolumn{2}{c}{ Yangpu } & \multicolumn{2}{c}{ Pudong } \\
\cline { 2 - 5 } & Walking & Cycling & Walking & Cycling \\
\hline \multirow{3}{*}{ distance } & $1.6 \%$ & Moderate Opening (MO) & \\
count & $9.1 \%$ & $2.4 \%$ & $0.2 \%$ & $4.2 \%$ \\
distance & $17.7 \%$ & $0.7 \%$ & $5.1 \%$ \\
count & $4.9 \%$ & Complete Opening $(\mathrm{CO})$ & \\
\end{tabular}

The accessibility benefits are more significant in the count-based metric, $b^{\text {count }}$, which measures the proportion of OD pairs that have sufficiently perceptible accessibility benefits. Our result shows that the accessibility improvements brought by $\mathrm{CO}$ in both cases reach about $40-50 \%$. That is to say, if all kinds of gates and walls are completely removed, nearly half of journeys from both communities will benefit from a distance reduction of more than $50 \mathrm{~m}$, which may bring residents a huge sense of accessibility improvement. For the MO scenario, the Yangpu community still displays significant accessibility benefits, 9.1\% for walking and $17.7 \%$ for cycling, which are far beyond the percentages revealed by $b^{\text {dist }}$. In contrast, $b^{\text {count }}$ in the Pudong case and MO scenario is much smaller than the Yangpu case and demonstrates little difference from $b^{\text {dist }}$. However, under the $\mathrm{CO}$ scenario, the benefits in the Pudong case surpass Yangpu distinctly, not only in distance savings but also in the count metric. We speculate that the reason is that the Pudong case is a renewed community that has only six unusable gates (fake and only for walking) but relatively tight walls, while the Yangpu case has 26 unusable gates, meaning the Pudong case benefits less from $\mathrm{MO}$, that is, opening the unusable gates, but more from $\mathrm{CO}$. This indicates that suitable opening policies regarding different gated communities may vary dramatically according to their characteristics, such as gates' configurations.

Another distinct pattern is that the improvements for cycling accessibility are generally higher than that for walking in all cases and all scenarios. This is because the Yangpu and Pudong cases have eight and four pedestrian gates, respectively, which are unimpeded for pedestrians but physically impassable for bicycles and cyclists. Since such gates are common in Shanghai and presumably also in other Chinese cities, the revealed accessibility benefits for cycling emphasize the appropriateness of the widespread implementation of opening such gates for bicycles.

\subsection{Accessibility Benefits Regarding Different Facilities}

The accessibility benefits of opening gates regarding different facilities are consistent with the overall trends in Section 4.1: the CO scenario has much more improvement than $\mathrm{MO}$, the count metric reveals larger proportions of perceptible trips, the Pudong case has fewer benefits in $\mathrm{MO}$, but more in $\mathrm{CO}$, and the improvements for cycling accessibility are generally higher than for walking.

However, there are still distinctions between the accessibility benefits regarding the four types of facilities. Table 3 presents the benefits of four facilities under sixteen combinational situations (two metrics, two opening scenarios, and two travel modes for two cases). The bus station demonstrates the largest accessibility improvements eight times out of the 16 situations. In contrast, although they are public transport facilities, the accessibility improvements of metro stations are polarized between the two cases. Trips from 
the Yangpu community to metro stations consistently have the least accessibility benefits, while the Pudong case benefits significantly for both walking and cycling, especially when measured by distance. We speculate that the reasons are: (1) metro stations are sparser than bus stations, which accounts for a smaller chance for accessibility benefit, and (2) the Pudong community is a renewed modern estate whose gate configuration is mainly based on considerations for private car convenience, so its gates are located more towards the arterial roads rather than metro stations.

Table 3. Accessibility benefits regarding different facilities.

\begin{tabular}{|c|c|c|c|c|}
\hline & Bus station & Metro Station & Daily Services & Sports and Entertainment \\
\hline \multicolumn{5}{|l|}{$b^{\text {count }}$} \\
\hline \multicolumn{5}{|c|}{ Moderate Opening } \\
\hline \multicolumn{5}{|l|}{ Yangpu } \\
\hline walking & $9.64 \%$ & $8.75 \%$ & $9.04 \%$ & $9.27 \%$ \\
\hline Cycling & $17.61 \%$ & $14.21 \%$ & $17.82 \%$ & $16.95 \%$ \\
\hline \multicolumn{5}{|l|}{ Pudong } \\
\hline walking & $1.00 \%$ & $0.63 \%$ & $0.65 \%$ & $0.79 \%$ \\
\hline Cycling & $6.19 \%$ & $7.40 \%$ & $5.00 \%$ & $5.20 \%$ \\
\hline \multicolumn{5}{|c|}{ Complete Opening } \\
\hline \multicolumn{5}{|l|}{ Yangpu } \\
\hline walking & $39.18 \%$ & $36.46 \%$ & $40.22 \%$ & $39.39 \%$ \\
\hline Cycling & $47.49 \%$ & $42.56 \%$ & $50.04 \%$ & $47.76 \%$ \\
\hline \multicolumn{5}{|l|}{ Pudong } \\
\hline walking & $50.63 \%$ & $48.41 \%$ & $49.85 \%$ & $49.52 \%$ \\
\hline Cycling & $52.91 \%$ & $51.80 \%$ & $51.92 \%$ & $51.62 \%$ \\
\hline \multicolumn{5}{|c|}{ Moderate Opening } \\
\hline \multicolumn{5}{|l|}{ Yangpu } \\
\hline walking & $1.98 \%$ & $0.69 \%$ & $1.64 \%$ & $1.97 \%$ \\
\hline Cycling & $3.39 \%$ & $0.76 \%$ & $2.60 \%$ & $2.71 \%$ \\
\hline \multicolumn{5}{|l|}{ Pudong } \\
\hline walking & $0.16 \%$ & $0.22 \%$ & $0.13 \%$ & $0.15 \%$ \\
\hline Cycling & $1.99 \%$ & $6.09 \%$ & $1.94 \%$ & $1.64 \%$ \\
\hline \multicolumn{5}{|c|}{ Complete Opening } \\
\hline \multicolumn{5}{|l|}{ Yangpu } \\
\hline walking & $6.83 \%$ & $2.94 \%$ & $5.96 \%$ & $5.74 \%$ \\
\hline Cycling & $8.17 \%$ & $3.01 \%$ & $6.87 \%$ & $6.44 \%$ \\
\hline \multicolumn{5}{|l|}{ Pudong } \\
\hline walking & $7.90 \%$ & $8.42 \%$ & $7.09 \%$ & $8.16 \%$ \\
\hline Cycling & $9.58 \%$ & $13.80 \%$ & $8.76 \%$ & $9.53 \%$ \\
\hline
\end{tabular}

Note: the row-wise maximum numbers are highlighted in bold.

Unlike the public traffic facilities above, the accessibility benefits regarding daily services and sports and entertainment appear to be the most stable. The benefits of these two types of facilities mostly coincide with the average value in Table 2 . For example, $b^{\text {distance }}$ and $b^{\text {count }}$ of these two facilities in the CO scenario are around $6-9.5 \%$ and $40.2-51.6 \%$, which are exactly within the range shown in Table 2 . This is because, since these two types of facilities are more widely and homogeneously distributed than public traffic facilities, residents can always get access to them conveniently through existing gates so that only a few trips may benefit significantly from newly added exits.

Moreover, the benefits of cycling still generally prevail over walking, indicating again that cyclists in Shanghai suffer more from GCs no matter what their destinations are. Table 3 demonstrates that merely opening the fake gates can bring around a $5 \%$ benefit for cyclists in Pudong, while a similar benefit for walkers is less than $0.8 \%$. Obviously, such a disparity may be due to fewer fake gates in the Pudong case, as discussed in Section 4.1. 


\subsection{Spatial Heterogeneity of the Benefits}

Spatial analyses show that significant heterogeneity of the benefits can be observed. Residents in the same community may have dramatically varying accessibility benefits, which are strongly determined by 1) their closeness to the corresponding opened gates in specific scenarios, and 2) the relative location of the building in the block.

Figure 4 illustrates the effect of the first factor, closeness to the opened gates. In the MO scenario (left column in Figure 4), residents within $200 \mathrm{~m}$ of the locked gates or pedestrian gates can receive benefits of $b^{\text {count }}$ as high as $40 \%$ for walking and cycling, though in the Pudong case, such a benefit is not common because it has only five fake gates. However, in the CO scenario, there exists almost no correlation between distance to opened gates and $b^{\text {count }}$ (right column in Figure 4). This is because, in the CO scenario, all the accessibility shortcomings regarding each pair of residents and facilities can be generally overcome since gates are added in every wall, as depicted in Figure 2. This result demonstrates that spatial heterogeneity caused by the first factor can be counteracted in the ideal opening scenario, though at great expense.
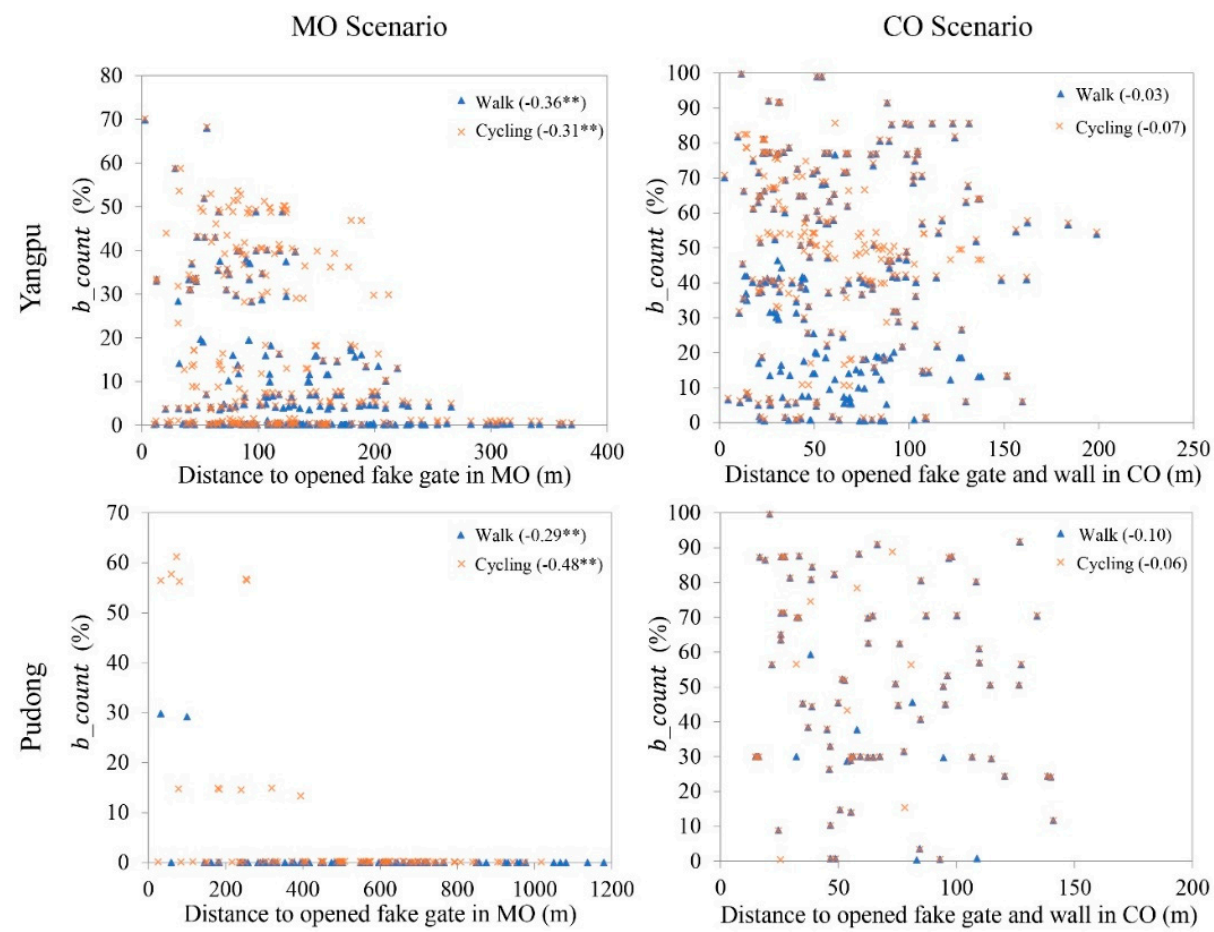

Figure 4. Residence locations against accessibility benefits in two scenarios. Note: the correlation coefficients between distance to gates and $b^{\text {count }}$ and the significance level in terms of each scenario and travel mode are given in brackets. ${ }^{* *} p<0.05$.

Figure 5 depicts the effect of the second factor, whether the location of a residential building is marginal or central. Firstly, residents who live in more central areas generally gain less benefit in the MO scenario than the $\mathrm{CO}$ scenario. This is natural; as shown in Figure 2, opening the fake gates has little influence on O1 to D4. However, the route O1-D4 will be significantly shortened when the walls are broken down in the CO scenario. On the contrary, residents who live near the edge have greater chances to improve their accessibilities in the MO scenario. Such a phenomenon can be seen in many blocks of both the Yangpu and Pudong cases in Figure 5. Secondly, those living near the edge and more adjacent to the wall benefit the most in the CO scenario. In Figure 5, the northwest block in Yangpu and the southern three blocks in Pudong are the best examples. This is because many trips of those living near the edge, such as O2-D2 and O4-D3 in Figure 2, are naturally more limited by the walls. Therefore, when gates are added by breaking down the wall in the CO scenario, they benefit significantly. 

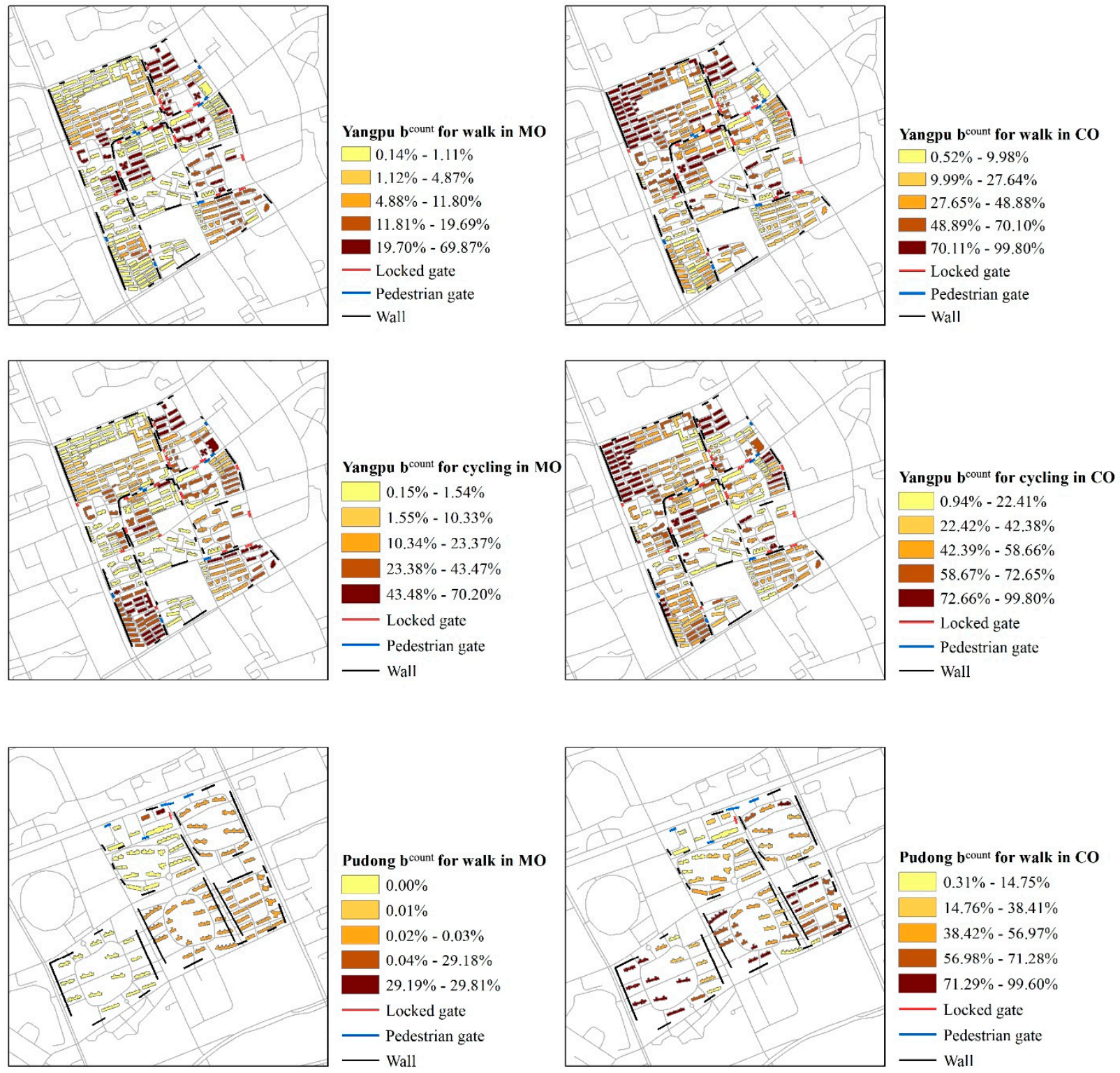

Pudong bount for walk in CO

$\begin{array}{r}\square .31 \%-14.75 \% \\ \hline\end{array}$

$14.76 \%-38.41 \%$

ए $38.42 \%-56.97 \%$

$56.98 \%-71.28 \%$

$71.29 \%-99.60 \%$

Locked gate

- Pedestrian gate
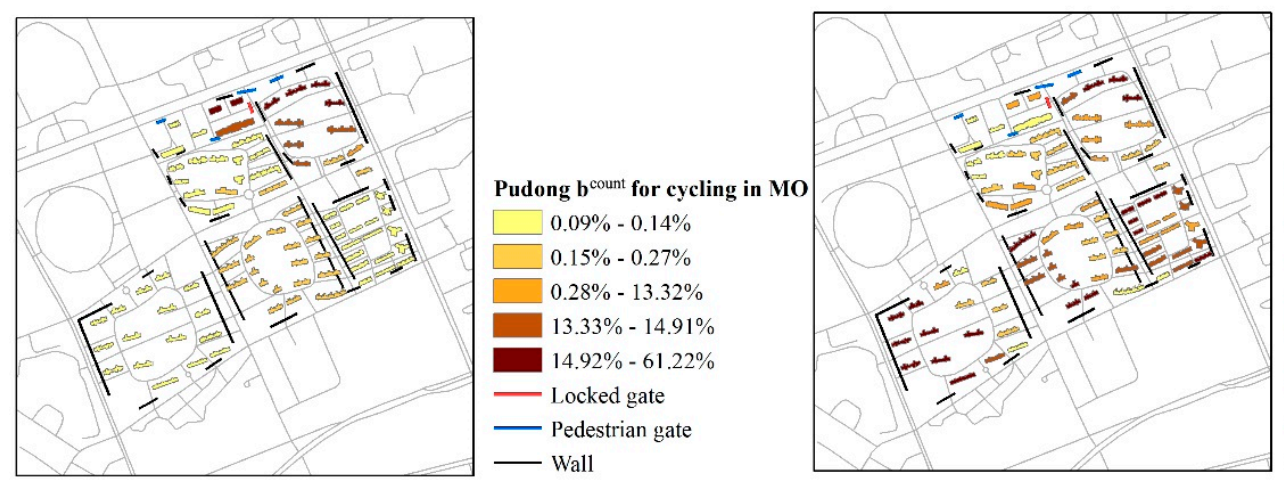

Pudong b $b^{\text {count }}$ for cycling in $\mathrm{CO}$

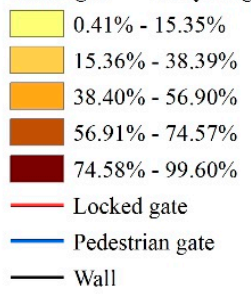

Figure 5. Spatial heterogeneity of $b^{\text {count }}$.

\subsection{Potential Risk Analyses}

This section analyzes the potential penetrating risk due to opening new gates. Since nearby citizens tend to cross the community for travel convenience, the security and living environment inside the community may be adversely affected. To measure such risk, 
it is assumed that if a trip originates from the buildings that are outside but within the neighboring $500 \mathrm{~m}$ of the case communities and receives an accessibility gain larger than $50 \mathrm{~m}$, it is considered likely to penetrate the community. Then, we propose another metric, risk count, which measures the proportion of such trips from outside the community.

The result shows that the penetrating risk is relatively marginal and far less than both our expectation and the reward. Compared to the overall benefits in Table 2, where 9-17\% of the internal ODs have their distances reduced by more than $50 \mathrm{~m}$, Table 4 shows that only $1 \%$ of external ODs may penetrate. In the CO scenario, although the risk ${ }^{\text {count }}$ reaches 5-7\%, benefitting internal ODs increase to $40-50 \%$. Again, the risk is far less than the reward. Actually, penetrating risks can be mitigated by detailed road and landscape design. For example, if roads within the community are joined to external urban arteries through twisted rather than a direct connection, it will be hard for outsiders who are unfamiliar with the community to see through and take shortcuts because of obscured vision.

Table 4. Potential risks from crossing traffic.

\begin{tabular}{ccccc}
\hline & \multicolumn{2}{c}{ Yangpu } & \multicolumn{2}{c}{ Pudong } \\
\cline { 2 - 5 } & Walking & Cycling & Walking & Cycling \\
\hline $\mathrm{MO}>50 \mathrm{~m}$ & $0.84 \%$ & $1.25 \%$ & $0.06 \%$ & $0.51 \%$ \\
$\mathrm{CO}>50 \mathrm{~m}$ & $4.68 \%$ & $5.64 \%$ & $7.10 \%$ & $7.19 \%$ \\
\hline
\end{tabular}

\section{Conclusions and Discussion}

Taking two typical GCs in Shanghai as examples, this study quantifies and analyzes the accessibility benefits of opening gated communities. Considering more realistic factors, the accessibility benefits are quantified in two opening scenarios with respect to four categories of facilities and for both pedestrians and cyclists. Quantitative analysis is carried out by combining activity models and the data from the Comprehensive Transportation Survey, census data, and online mapping services. The major findings are:

(1) Opening GCs can indeed bring sufficiently perceptible accessibility. In the MO and $\mathrm{CO}$ scenarios, up to $17 \%$ and $52 \%$ of the residents could experience accessibility gains exceeding $50 \mathrm{~m}$, respectively.

(2) Cycling benefits more than walking in all cases and all opening GC scenarios, which can be attributed to the pedestrian gates. Considering the wide distribution of such gates in China, to open them may be essential for creating a bicycle-friendly environment.

(3) The types of GCs and facilities matter. Compared to the conventional GCs that are derived from working units, the newly established modern GCs in Shanghai may have fewer benefits in MO but more in $\mathrm{CO}$. In terms of different facilities, bus stations demonstrate the largest accessibility gains while metro stations are polarized between the two cases, which is probably due to their spatial distribution.

(4) The locations of residential buildings also matter. The accessibility benefit of a residential building is highly determined by its closeness to the corresponding opened gates and its relative location in the block. However, complete opening (CO) can erase the spatial heterogeneity, though at great expense.

(5) In $\mathrm{MO}$ and $\mathrm{CO}$ scenarios, only $1 \%$ and $5-7 \%$ of external ODs may penetrate, respectively. The risk is far less than both our expectations and the reward.

Based on the findings in this study, several design guidelines can be proposed. Firstly, they propose strong support for opening the two GCs considering the significant overall benefits, comparatively low risk, and stable accessibility benefits in terms of metro/bus stations, which may further improve the utilization of public transit in the two communities. Secondly, the results suggest that it is more efficient and cost-effective for the Yangpu GC to implement $\mathrm{MO}$, namely, opening all the existing fake gates, to gain a significant benefit. For the newly established Pudong GC, however, CO is a more effective option. In spite of this, we strongly recommend that pedestrian gates in the two cases are opened before any radical policies are implemented. To generalize these guidelines to other GCs in Shanghai 
or even other cities requires numerous similar experiments. The targeted guidelines may be dramatically different in other cases. Therefore, we emphasize again the necessity and appropriateness of applying the proposed evaluation before making targeted policies.

Moreover, opening GCs could have more side effects than measured in this paper. For instance, to mitigate existing transportation conflicts, the key point is not merely the openness of GCs but a rational urban traffic plan. An advanced road network plan should synthetically increase its capacity for both cyclists and pedestrians. Second, accompanied by opening up, the allocation of public resources becomes the primary issue. Government finances are already tight in many parts of China, indicating that a radical change in the pricing model for public services will be inevitable to follow the international open block system. The prosperity of community public life can be realized only after the property rights, privacy, convenience, and sharing of public facilities are guaranteed.

This study still has several limitations. First, since the two opening scenarios are confined to China's existing GCs, the design guidelines are more suitable for the renewal of such GCs rather than the open design of new neighborhoods. Despite this, both of the two opening scenarios are derived from current situations of typical Chinese GCs, which are easy to implement. Second, the study only assesses two cases rather than a variety of samples for analysis, which inevitably leads to some accidental results and affects the contribution to policy implications.

To address the first limitation, more inclusive opening scenarios could be tested. For example, recent studies have suggested that "hutong", a traditional open block pattern in China, provides localized opened community experiences that are worth learning from [40]. As for the second limitation, we do believe that the proposed method can be generalized to measure the benefit of opening other GCs. Moreover, this paper emphasizes the importance of objective benefits and how to measure them but neglects the subjective satisfaction. Therefore, both the parameters in our method and the proposed opening up guidelines could be refined by combining them with further investigations and interviews.

Author Contributions: Conceptualization, S.Y., W.T., and L.Y.; Formal analysis, S.Y.; Methodology, L.Y.; Project administration, W.T.; Supervision, W.T.; Writing—original draft, S.Y.; Writingreview and editing, W.T. and L.Y. All authors have read and agreed to the published version of the manuscript.

Funding: This study is supported by the Fundamental Research Funds for the Central Universities (No. 2682019CX54).

Institutional Review Board Statement: Not applicable.

Informed Consent Statement: Not applicable.

Data Availability Statement: Data sharing not applicable. No new data were created or analyzed in this study. Data sharing is not applicable to this article.

Conflicts of Interest: The authors declare no conflict of interest.

\section{References}

1. Xie, Y.; Costa, F.J. Urban planning in socialist China: Theory and practice. Cities 1993, 10, 103-114. [CrossRef]

2. Deng, F. Work unit and private community in the evolution of urban planning in contemporary China. Plan. Theory 2018, 17, 533-550. [CrossRef]

3. Breitung, W. Enclave Urbanism in China: Attitudes Towards Gated Communities in Guangzhou. Urban Geogr. 2012, 33, 278-294. [CrossRef]

4. Wu, F. Rediscovering the 'gate'under market transition: From work-unit compounds to commodity housing enclaves. Hous. Stud. 2005, 20, 235-254. [CrossRef]

5. Qian, X.; Cai, Y.; Yin, C. Driving Force of Grassroots Self-governance in Beijing's Neighborhoods: Social Capital, Community Network and Community Service Motivation. Lex Localis 2019, 17, 159-177. [CrossRef]

6. Xu, M.; Yang, Z. Design history of China's gated cities and neighbourhoods: Prototype and evolution. Urban Des. Int. 2009, 14, 99-117. [CrossRef]

7. Xiao, Y.; Lu, Y.; Guo, Y.; Yuan, Y. Estimating the willingness to pay for green space services in Shanghai: Implications for social equity in urban China. Urban. For. Urban. Green. 2017, 26, 95-103. [CrossRef] 
8. Miao, P. Brave new city: Three problems in Chinese urban public space since the 1980s. J. Urban Des. 2011, 16, 179-207. [CrossRef]

9. Wang, Z.; Li, L.; Li, Y. From super block to small block: Urban form transformation and its road network impacts in Chenggong, China. Mitig. Adapt. Strateg. Glob. Chang. 2015, 20, 683-699. [CrossRef]

10. Normile, D. China Rethinks Cities. J. Sci. 2016, 352, 916-918. [CrossRef]

11. Song, W.; Wu, Q. Gentrification and residential differentiation in Nanjing, China. Chin. Geogr. Sci. 2010, 20, 568-576. [CrossRef]

12. Abramson, D.B. Haussmann and Le Corbusier in China: Land control and the design of streets in urban redevelopment. J. Urban Des. 2008, 13, 231-256. [CrossRef]

13. Liao, K.H.; Wehrhahn, R.; Breitung, W. Urban planners and the production of gated communities in China: A structure-agency approach. Urban Stud. 2019, 56, 2635-2653. [CrossRef]

14. Makhale, S.; Landman, K. Gating and conflicting rationalities: Challenges in practice and theoretical implications. Int. Plan. Stud. 2018, 23, 130-143. [CrossRef]

15. Wang, H.; Pojani, D. The challenge of opening up gated communities in Shanghai. J. Urban Des. 2020, 25, 505-522. [CrossRef]

16. Blakely, E.J.; Snyder, M.G. Fortress America: Gated Communities in the United States; Brookings Institution Press: Washington, DC, USA, 1997.

17. Atkinson, R.; Flint, J. Fortress UK? Gated communities, the spatial revolt of the elites and time-space trajectories of segregation. Hous. Stud. 2004, 19, 875-892. [CrossRef]

18. Iossifova, D. Borderland urbanism: Seeing between enclaves. Urban Geogr. 2015, 36, 90-108. [CrossRef]

19. Miao, P. Deserted streets in a jammed town: The gated community in Chinese cities and its solution. J. Urban Des. 2003, 8, 45-66. [CrossRef]

20. Li, S.M.; Zhu, Y.S.; Li, L.M. Neighborhood Type, Gatedness, and Residential Experiences in Chinese Cities: A Study of Guangzhou. Urban Geogr. 2012, 33, 237-255. [CrossRef]

21. Atkinson, R. Padding the bunker: Strategies of middle-class disaffiliation and colonisation in the city. Urban Stud. 2006, 43, 819-832. [CrossRef]

22. Douglass, M.; Wissink, B.; van Kempen, R. Enclave urbanism in China: Consequences and interpretations. Urban Geogr. 2012, 33, 167-182. [CrossRef]

23. Lin, L.Y.; Han, H.Y.; Yan, W.L.; Nakayama, S.; Shu, X.F. Measuring Spatial Accessibility to Pick-Up Service Considering Differentiated Supply and Demand: A Case in Hangzhou, China. Sustainability 2019, 11, 3448. [CrossRef]

24. Lu, T.T.; Zhang, F.Z.; Wu, F.L. Place attachment in gated neighbourhoods in China: Evidence from Wenzhou. Geoforum 2018, 92, 144-151. [CrossRef]

25. Wang, Y.; Peng, Z.Y.; Chen, Q. The choice of residential layout in urban China: A comparison of transportation and land use in Changsha (China) and Leeds (UK). Habitat Int. 2018, 75, 50-58. [CrossRef]

26. de Duren, N.R.L. Gated communities as a municipal development strategy. Hous. Policy Debate 2007, 18, 607-626. [CrossRef]

27. de Duren, N.L. Planning a la carte: The location patterns of gated communities around Buenos Aires in a decentralized planning context. Int. J. Urban Reg. Res. 2006, 30, 308-327. [CrossRef]

28. Kovacs, Z.; Hegedus, G. Gated communities as new forms of segregation in post-socialist Budapest. Cities 2014, 36, 200-209. [CrossRef]

29. Xu, F. Gated communities and migrant enclaves: The conundrum for building 'harmonious community/shequ'. J. Contemp China 2008, 17, 633-651. [CrossRef]

30. Hansen, R.S. Public space in current debate: A critical reflexion about post-modern urbanism. Eure-Rev. Latinoam. Estud. Urbano Reg. 2002, 28, 5-19.

31. Guan, C.H.; Srinivasan, S.; Nielsen, C.P. Does neighborhood form influence low-carbon transportation in China? Transp. Res. Part D Transp. Environ. 2019, 67, 406-420. [CrossRef]

32. Sun, G.B.; Wallace, D.; Webster, C. Unravelling the impact of street network structure and gated community layout in developmentoriented transit design. Land Use Policy 2020, 90. [CrossRef]

33. Dong, L.; Rinoshika, A.; Tang, Z.X. Dynamic Evaluation on the Traffic State of an Urban Gated Community by Opening the Micro-Inter-Road Network. Technologies 2018, 6, 71. [CrossRef]

34. Yao, Y.; Hong, Y.; Wu, D.; Zhang, Y.; Guan, Q. Estimating the effects of "community opening" policy on alleviating traffic congestion in large Chinese cities by integrating ant colony optimization and complex network analyses. Comput. Environ. Urban Syst. 2018, 70, 163-174. [CrossRef]

35. Hamama, B.; Liu, J. What is beyond the edges? Gated communities and their role in China's desire for harmonious cities. City Territ. Archit. 2020, 7, 1-12. [CrossRef]

36. Webster, C.; Ruan, J.; Sun, G. Private gains and social costs of China's gated communities. In Handbook of Cultural Security; Edward Elgar Publishing: Cheltenham, UK, 2018.

37. Sun, G.B.; Webster, C.; Chiaradia, A. Ungating the city: A permeability perspective. Urban Stud. 2018, 55, 2586-2602. [CrossRef]

38. Cai, M.; Li, J.; Wang, Z.; Wang, H. Evaluation of external costs in road transport under the openness of a gated community. Front. Earth Sci. 2020, 14, 1-12. [CrossRef]

39. Yang, Y.; Diez-Roux, A.V. Walking distance by trip purpose and population subgroups. Am. J. Prev. Med. 2012, 43, 11-19. [CrossRef]

40. Liu, Q.; Zhao, M.; Xu, F. The Reference Significance of the Space Form of Hutong to the Opening of the Residential Area. Urban Plan. Int. 2019, 34, 96-102. [CrossRef] 